\title{
Experiência e pobreza na narrativa de João Gilberto Noll
}

Rafael Campos Quevedo I UFES

Resumo: Discussão em torno do problema da escrita de João Gilberto Noll a partir do pressuposto de que esta é um registro do definhamento da experiência e da memória, elementos que dão suporte, segundo Walter Benjamin, à figura do Narrador. O artigo procura indagar sobre como se configura a problemática do narrador da obra de Noll do ponto de vista da "falta do ter o que narrar", espécie de paradoxo emblemático da conjuntura em que a obra do escritor gaúcho se insere. Este trabalho é, também, uma pergunta sobre que tipo de posicionamento a escrita de Noll oferece como resposta a essa conjuntura. O corpus é composto por quatro romances: Hotel atlântico, Harmada, A céu aberto $e$ Berkeley em Bellagio.

Palavras-chave: narrador, experiência, João Gilberto Noll.

"O meu irmão chegou mais perto do meu ouvido e pediu que orássemos, contou que criara uma 'Prece à derrota' que é a situação na qual não temos mais nada a perder e de mãos vazias erguemos essa reza feito uma ereção ao silêncio do céu, quando compreendemos enfim que não há mais nada a dizer."

A céu aberto 
Talvez a mais significativa de todas as recorrências dos quatro romances de Noll que tomamos como objeto deste comentário seja a que se refere ao fato de que em Hotel atlântico (1986), Harmada (1993), A céu aberto (1996) e Berkeley em Bellagio (2002), o protagonista sofre, ao final dessas narrativas, algum tipo de colapso com a linguagem, seja na forma de impotência total ou parcial dos sentidos (mudez ou surdez como em Hotel atlântico e Harmada); seja no conflito entre língua materna e língua estrangeira (Berkeley) ou, simplesmente, na encenação de uma mudez ( $A$ céu aberto). A idéia de se chegar até o mutismo ou a alguma forma de privação de um ou alguns dos sentidos que dizem respeito à faculdade da comunicação pode ser entendida, a nosso ver, sob dois prismas: o da degeneração e o do triunfo. No primeiro caso, emudecer pode significar, pelo viés da queda, a amputação de uma faculdade essencial, sem a qual o indivíduo se desumaniza, torna-se um mutilado, expulso da comunidade do lógos onde se abriga a humanidade como forma de se "proteger" da ameaçadora ancestralidade animal. Sob o outro ponto de vista, a mudez pode ser vista não como perda, mas como coroamento, ascensão. O indivíduo salta sobre o fosso do qual a linguagem se pretende ponte e alcança, sob a forma do silêncio, a consciência, de natureza mística, a partir da qual a linguagem torna-se absolutamente desnecessária. Nesse caso, é ela, a linguagem, que é vista como precariedade e insuficiência. O silêncio, por sua vez, é almejado como a instância última, não do conhecimento conceitual e discursivo (lógos), mas da sabedoria mística, espécie de superação do hiato entre homem e mundo.

Esses dois modos de encarar o problema da linguagem (ou da ausência dela) são efetivamente contraditórios entre si, pois, como vimos, um remonta à tradição ocidental do discurso, do conceito, do lógos como forma de cifragem universal da realidade. Escusado é dizer que tal tradição afunda suas raízes na história do pensamento filosófico e ocidental e se espraia sobre as demais dimensões da realidade humana, da ciência à política. A outra, por sua vez, participa do universo oriental de tradição mais espiritualista cujas fontes podem se remeter, por exemplo, à sabedoria chinesa ou hindu.

É possível que essas duas possibilidades coexistam como pano de fundo das circunstâncias que convergem para que os personagens de Noll rasguem as malhas da linguagem? Tais devem ser, portanto, os problemas condutores desta reflexão: um diz respeito a uma questão "interna" aos romances em questão, ou seja, trata-se de saber o que significa, no plano da "fábula", o fato de os personagens esbarrarem na questão do silêncio. O outro transcende a trama e os personagens 
para chegar à realidade contextual com a qual a escrita de Noll dialoga. Tal aspecto do problema pode ser enunciado da seguinte forma: no âmbito da narrativa de Noll, assim como para o lugar dessa escrita no tempo em que ela se insere, o que significa ou como se dá à problemática do contar e do calar, da fala e do silêncio? Uma consideração prévia: as duas perguntas encontram-se imbricadas e as respostas a ambas implicam-se mutuamente.

Estamos de acordo com a professora Nizia Villaça ao situar, via Adorno e Benjamin, o problema da narrativa contemporânea dentro do paradoxo da pergunta: qual o lugar do narrador quando não se tem mais o que narrar? Servindonos de alguns elementos da crítica benjaminiana de forma um tanto intempestiva (o que significa menos propor uma leitura de Noll via Benjamin do que tomar algumas das reflexões do pensador alemão como ponto de partida a fim de levarmos a cabo nossos propósitos argumentativos), tentaremos apontar, na escrita de João Gilberto Noll, um testemunho dessa problemática, como, também, uma tomada de posição frente a ela.

Em texto de 1936 intitulado O narrador, Walter Benjamin relaciona Experiência, Memória e Narrativa para mostrar como o atrofiamento das duas primeiras acarretaria a total extinção da última. O arquétipo maior da Narrativa seria a épica. Nela, a Experiência, no sentido forte de Erfabrung, possibilitaria ao Narrador o "ter o que dizer": "A experiência que passa de pessoa a pessoa é a fonte a que recorreram todos os narradores". ${ }^{1}$ À figura do Narrador corresponderia, portanto, a do sujeito que dá forma à matéria da experiência coletiva fundindo-a com a sua própria experiência individual, de modo que seja próprio à natureza do que é narrado um fundo de "dimensão utilitária":

Essa utilidade pode consistir seja num ensinamento moral, seja numa sugestão prática, seja num provérbio ou numa norma de vida - de qualquer maneira o narrador é um homem que sabe dar conselhos. [...] O conselho tecido na substância viva da existência tem um nome: sabedoria. A arte de narrar está definhando porque a sabedoria - o lado épico da verdade - está em extinção.

1. Benjamin, 1985, p. 198.

2. Benjamin, 1985, p. 200-201. 
A partir disso, pergunta Benjamin em Experiência e pobreza (1933):

Quem encontra ainda pessoas que saibam contar histórias como elas devem ser contadas? Que moribundos dizem hoje palavras tão duráveis que possam ser transmitidas como um anel, de geração a geração? Quem é ajustado, hoje, por um provérbio oportuno? Quem tentará, sequer, lidar com a juventude invocando sua experiência?

Tais perguntas, se por um lado sugerem o quadro de um empobrecimento cultural (definhamento da sabedoria coletiva), por outro apontam para uma perspectiva positiva. Trata-se da acepção benjaminiana de barbárie. A positividade dessa barbárie está em que, se a sabedoria e a tradição ruíram, a condição de construir algo novo e seguir adiante está dada como um campo aberto de possibilidades.

No que diz respeito às histórias de Noll, tudo se passa como se elas fossem engendradas "durante" o processo mesmo da escrita, ou seja, o conteúdo da narrativa não precederia o texto em si, mas passaria a existir de maneira concomitante ao próprio ato de narrar. Isso nos sugere a possibilidade de estarmos diante de uma escrita que parte do "grau zero" da memória, que não se origina de um centro irradiador de onde se poderia jorrar uma experiência a ser comunicada, mas tudo se passa como se tal escrita fosse a confissão e o testemunho dessa "pobreza".

Algumas passagens das obras escolhidas concorrem para corroborar tal posicionamento e, embora elas sejam proferidas por entidades ficcionais, entendemos que esses trechos se coadunam sensivelmente com a própria idéia de escrita para o autor. De um modo geral, essa característica aparece nas várias ocasiões nas quais o que está em jogo é o ato de contar histórias, como em Harmada, em que o protagonista, no período em que passa morando num asilo, assume o papel do contador de histórias para os internos. Com o tempo, ouvir histórias acaba se tornando a principal ocupação dos albergados, que passam a se interessar cada vez mais pela figura daquele narrador, que assim fala do seu processo de invenção das histórias:

$\mathrm{Eu}$, a bem da verdade, jamais preparava as narrativas que desembocavam pela minha boca. O rumo do desenrolar das tramas se dava só ali, no ato

3. BENJAMIN, 1985, p. 114 
de proferir a ação. Aliás, detestava pensar previamente acerca do que teria a contar. Eu me deixava conduzir pela fala, apenas isso, e esta fala nunca me desapontou, ao contrário, esta fala só soube me levar por inesperados e espantosos episódios.

De bastante significação é também o trecho de $A$ céu aberto que se refere ao "teatro da aparição", nome dado por um personagem a uma peça que está em processo de concepção e que consiste no diálogo entre dois "desmemoriados". Um não possui o mínimo de memória de si mesmo, mas "guarda na mente todos os acontecimentos do mundo" e o outro não tem nenhuma lembrança de qualquer acontecimento público, mas é capaz de rememorar um acontecimento mais remoto e mais banal possível de sua vivência pessoal. Ao ser indagado sobre o enredo da peça, um deles responde: "Enredo? [...] - Sim, o que acontece entre esses dois? - Ah! Os dois falam tanto mas tanto sobre seus fluxos próprios de memórias que jamais coincidem que jamais se interpenetram [...]" .

Essas duas passagens nos são por ora bastante significativas, pois ambas ajudam a ilustrar a imagem do narrador Noll na condição de antípoda do Narrador benjaminiano, basicamente sob o seguinte aspecto: por partir do que chamamos de o "marco zero" da memória (sem o auxílio da deusa Mnemosýne, "a deusa da reminiscência [que] era para os gregos a musa da poesia épica" ${ }^{7}$ Se quisermos ir mais longe nessa aproximação, basta lembrarmos dos dois pólos da experiência que, segundo Benjamin, estariam fundidos na "fala" do Narrador: a experiência individual e a experiência coletiva. Na passagem de $A$ céu aberto, a cada um dos desmemoriados falta justamente uma "parte" da experiência (ora a individual, ora a coletiva) inviabilizando por completo a possibilidade de uma totalização. E é justamente dessa impossibilidade que decorre o tipo de narração

4. NOLL, 2003, p. 40. Sobre esse processo, conferir também as histórias que o protagonista João (Berkeley em Bellagio) contava à menina Sarita (filha de Léo): "histórias fabricadas na hora, como fazia meu pai à noite [...]" (NOLL, 2003, p. 93).

5. NOLL, 1996, p. 98.

6. NOLL, 1996, p. 99. Sobre a ausência de enredo, conferir Berkeley: "ele pergunta meio irritado o que acontece de fato nos meus livros, digo que não sei contar talvez porque nada aconteça de fato nessas minhas histórias [...]" (NOLL, 2003, p. 59).

7. BENJAMin, 1985, p. 211. 
que "inventa na hora" as histórias e que, para tomarmos de empréstimo um termo do personagem, chamaremos de a "escrita do fluxo". Em outras palavras, e com uma certa reverberação benjaminiana, poderíamos dizer que tal escrita não provém de um manancial de sabedoria que a precede, ela não rememora uma experiência, nem dá "conselhos". Desse modo, o "deixar-se conduzir pela fala" (Harmada) abre para uma escrita do fluxo de uma vivência (Erlebnis) que vai se fazendo durante o ato mesmo de contar. E, por esse motivo, tal escrita torna-se o registro ou o testemunho (ou ainda a confissão) da pobreza da experiência, tal como tentaremos demonstrar mais adiante.

É importante desenvolvermos mais um pouco a noção de transitoriedade em Noll antes de passarmos para o ponto a que fizemos referência no final do parágrafo anterior. Vale frisar, por exemplo, que a idéia do fluxo contínuo da narrativa perpassa absolutamente toda a ambientação dos textos do autor, ${ }^{8}$ incluindo a própria caracterização de seus personagens.

Referimo-nos, aqui, em especial, à questão das "identidades em trânsito" dos personagens, assim como a toda sorte de deslocamentos operados dentro da narrativa. "Eu precisava ir" é a exigência mais imperativa de todos os protagonistas dos romances abordados neste artigo. Basta lembrarmos do João de Berkeley em Bellagio: "eu vou embora para um lugar que ainda não feito" ${ }^{10}$ e da sua indagação na seguinte passagem: "sou alguém que se desloca para permanecer fixo?" "Talvez a imagem que melhor abarque essa idéia do fluxo contínuo, na apreensão que os personagens possuem de si próprios e da realidade, seja a do córrego. A alegoria heraclítica do devir eterno é a afirmação de que a imutabilidade não é propriedade nem da realidade humana nem do cosmos, pois nunca banhamos no mesmo rio duas vezes já que nem nós, nem o próprio rio, somos os mesmos no instante imediato ao primeiro mergulho, ou seja: tudo flui. A imagem do córrego "onde no recreio banhávamos os pés" que abre A céu aberto é, portanto, a

8. Embora fazendo referência aos contos e não aos romances de Noll, parece-nos válida a distinção entre contos de enredo e contos de atmosfera (dentro do qual os contos de Noll estariam inseridos) que Luiz Gonzaga Marchezan faz no artigo "O hipotexto de Noll" (ver referências).

9. NOLL, 1995, p. 15.

10. NOLL, 2003, p. 18.

11. NOLL, 2003, p. 37.

12. NOLL, 2003, p. 9. 
metáfora predominante das narrativas em questão. Isso poderia justificar, por exemplo, a revolta dos personagens diante da fixidez do espelho ou da fotografia. Nas passagens em que aparecem espelhos, estes quase sempre servem para refletir a decrepitude do rosto e os sinais da velhice (as marcas do fluxo do tempo, portanto). Sobre a fotografia, lembremos a passagem de Berkeley em que o protagonista amassa um retrato encontrado no bolso da calça e, em seguida, o introduz no ânus. Ódio para com o fixo ou um gesto simbólico do desejo de incorporar ao corpo a imutabilidade da imagem fotográfica? ${ }^{13}$

Eis que esse tipo de representação caótica de fragmentos que se rebelam a qualquer tentativa de totalização ${ }^{14}$ (cuja condição poderia ser compreendida como a renúncia a um projeto a priori de literatura e a liberação da escrita à sua própria sorte) talvez seja, em si mesmo, uma modalidade de projeto literário. Este, por sua vez, visaria fazer da própria ordem ficcional do texto literário o correlato do aspecto caótico da realidade por detrás da aparência de ordem e causalidade que os séculos de pensamento racional tentaram revesti-la. Assim, a literatura de Noll, rompendo com a linearidade e até mesmo com a coerência da narrativa realista, estaria, na verdade, a serviço de uma outra ordem do real, mais autêntica, portanto, uma vez que não lançaria mão dos falsos sucedâneos de organicidade e logicidade do realismo tradicional. É possível rastrear indícios dessa idéia em algumas passagens dos romances escolhidos. Optamos, aqui, pela passagem de $A$ céu aberto cuja fala do irmão/mulher do protagonista trata sobre a teoria de um filósofo sueco que falava da verdadeira realidade como caos e os empreendimentos da lógica como ficção e mentira:

Um filósofo sueco [...] que dizia que os homens tinham nascido para associarem as coisas que viviam em eterno desconsolo por estarem soltas, alheias, desconexas, amputadas deste monumento que parece reinar no céu à noite - o drama? é que essa associação das coisas efetuadas pelos mortais é regida pelo puro acaso, pois trata-se apenas de uma construção mental e não do eco de alguma realidade; dizia ele que o homem para ser minimamente feliz deveria fazer de conta que acredita nessa construção, só isso: o segredo da serenidade de espírito estava na capacidade de fingir que se aceita, sim, que se aceita essa louca fabulação para se

13. A idéia da nostalgia pelo fixo será retomada no final deste trabalho juntamente com a questão do silêncio levantada na primeira página.

14. Ver VILLAÇA, 1996, p. 109. 
alcançar uma espécie de impermeabilidade entre essa grande falha do Nexo, é, assim mesmo, com $\mathrm{N}$ maiúsculo, pois esse conceito aí é uma casa que alugamos em certos períodos para nos abrigarmos da guerra entre todas as coisas avulsas [...] - ou seja, [...] o despedaçamento da vida deve ser curado com a grande mentira da unidade, e disso não podemos fugir, gostou?

Como se vê na citação transcrita anteriormente, o que chamamos realidade é o grande engodo, é a "ficção" no sentido negativo de mistificação, ocultação de um verdadeiro estado de coisas cuja única lei é a da aleatoriedade e da "caoticidade". Daí que a existência humana assemelha-se à representação cênica. A vida inteira fingimos que a ordem é uma propriedade do mundo e que a lógica não é uma projeção do desejo humano de afugentar os perigos que uma realidade fora de uma determinada organização poderia nos impingir. Várias são as passagens de outros romances de Noll que trazem essa marca, como esta de Harmada:

[...] pois é, eu fui um artista, um ator de teatro. E, de lá para cá, desde que abandonei ou fui abandonado pela profissão, não sei, desde então já não consigo mais fazer qualquer outra coisa [...] tudo aquilo que eu faço é como se estivesse representando, entende? Se pego uma pedra aqui e a levo até lá me dá um negócio por dentro, como se fosse trilhões de vezes mais pesado carregar esta mentira de carregar a pedra do que a própria pedra, não sei se você me entende, mas o caso é grave, acredite. [...] Eu e você aqui sabe?, tudo isto que estou a te falar, não acredite em nada, é uma repelente mentira, eu não sou de confiança, não, não acredite em mim.

Isso posto, passemos às considerações finais deste comentário tentando ligar entre si as várias questões que foram levantadas até o momento.

Esboçamos, num primeiro instante, via Benjamin, a situação paradigmática, conquanto paradoxal, da situação hodierna do Narrador quando "não se tem mais o que narrar". Argumentamos, em seguida, em torno da idéia de que a escrita de Noll é um "lugar" privilegiado para a constatação desse problema e que sua produção ostenta o vínculo a tais sintomas, como mostram algumas

15. NOLL, 1996, p. 123-124. (Grifos nossos).

16. NOLL, 2003, p. 24. 
abordagens que fizemos tanto sobre a sua escrita quanto sobre determinadas recorrências internas, da própria "fábula" dos romances em questão. Resta, agora, discutirmos acerca do "posicionamento" do universo da produção literária de João Gilberto Noll (pelo menos a pequena parte aqui delimitada, é bom que lembremos) diante do quadro aqui esboçado e entendermos o que isso tem a ver, além do que já foi antecipado, com a questão do colapso da linguagem, recorrência de forte valor significativo para os quatro romances em questão.

Quando Noll opta (ou acata) por dar vazão à linguagem errante, despretensiosa quanto ao encadeamento dos fatos que apresenta; quando ele assume o devir e o incorpora como ritmo de seu verbo, transforma sua narrativa numa expressão da barbárie, aquela que Benjamin apontou como horizonte de possibilidade, quando a cultura livra-se do peso da tradição que lhe enverga os ombros e pode agora erguer e edificar o novo: "Pois o que resulta para o bárbaro dessa pobreza de experiência? Ela o impele a partir para frente, a começar de novo, a contentar-se com pouco, sem olhar nem para direita nem para esquerda”.

A fidelidade de Noll ao seu próprio tempo impede-o, no entanto, de ser um construtor. Expliquemos o inusitado de tal sentença. Ao falarmos em termos de "espírito da época", estamos nos referindo a uma configuração cultural e artística a partir da qual o "novo" perdeu o valor de leitmotiv da criação e da experimentação artísticos. Nesse sentido é que a escrita de Noll presta fidelidade a esse esvaziamento afirmando que, se não há o que narrar, liberemos a fala à sua própria aventura e deixemos que seu fluxo errante nos conduza a insuspeitados sítios e que isso, de alguma maneira, possa ser, para nós leitores, uma forma de experiência. Não esperemos, no entanto, um conteúdo de verdade que possa ser passado adiante, uma sabedoria que "aconselhe", porque não há uma Erfabrung a ser compartilhada. Não esperemos, por fim, que a leitura de Noll nos ajude a regar utopias ou que nos capacite a sonhar um futuro, porque seria pedir de tal literatura algo que ela não pretende, algo que ela não ousou prometer. Eis, segundo entendemos, a postura de tal literatura a que nos referíamos anteriormente.

As considerações acima não nos devem induzir ao equívoco de concluir que os romances de Noll sugerem uma estética da resignação ou do apaziguamento quietista diante da emblemática morte das "verdades" que sustentavam as Narrativas. Existe, decerto, qualquer coisa na literatura de Noll que se quer reativa, embora não proponha caminhos, que se quer síntese, embora só

17. BENJAMIN, 1993, p. 116. 
se debata entre fragmentos, que quer descanso, embora não cesse de se deslocar e de errar sem rumo em eternas viagens sem um télos definido. Existe, nos livros por nós observados, uma nostalgia por um centro, por uma estabilidade que, no plano da linguagem, pode ser traduzida pelo silêncio. A fala convulsiva das narrativas de Noll quer calar, o fluxo da língua almeja o silêncio como a instância última de uma eloqüência absoluta.

Lembremos de Cris, em Harmada, que é internada no asilo porque tentou arrancar a língua a fim de parar de escutar a própria voz interior. ${ }^{18}$ Lembremos da figura de um velho em $A$ céu aberto

[...] que não morria por não conseguir parar de falar, ele falava o tempo todo, não dormia, não enunciava uma única vez o nome da morte [...] sem parar de falar, ele contava o nascimento, a jornada pelo tempo adentro, $[\ldots]$ as vitórias da raça do nosso inimigo seu povo, e veio então o herói cujo nome ninguém sabe dizer exatamente [...] e que como golpe de misericórdia, sei lá, digamos dessa maneira, ele veio e cortou a língua do tal velho do povo inimigo que não parava de contar as glórias de sua pátria [...] e cortou com um facão a língua do outro, do nosso inimigo. ${ }^{19}$

Pensemos nessas imagens enquanto volição ao estancamento de um fluxo. Especialmente no caso em questão, trata-se de uma hemorragia verbal, mas que, somando-se a outras circunstâncias (uma vez que, como dissemos, personagens e "atmosferas" em Noll são representadas enquanto fluxos) pode ser entendida como um fator de volição mais pungente de encontrar repouso, de estancar o devir heraclítico na estagnação parmenídica do ser, idêntico a si mesmo: o ser que "É". Isso está patente, por exemplo, no gosto pelo telúrico do personagem de Harmada, sempre se misturando à terra, ${ }^{20}$ ou da admiração diante do estado mineral, presente em A céu aberto:

Vejo esta pedra. Me ajoelho. Toco nela. A pedra tem uma grata aspereza. Sou cego, não enxergo mais. Enquanto apalpo a aspereza da pedra não

18. NOLL, 2003, p. 51.

19. NOLL, 1996, p. 22.

20. "e começou a passar lama pelo rosto, pelo corpo todo [...]" (NOLL, 2003, p. 89). 
tenho nada para olhar. Um dia serei uma delas, jazendo quem sabe no topo de um monte ou talvez no escuro do abrigo antiaéreo que tem na ponta sul do lago, intacto! Existem dias sim em que me canso de ser dente. [...] Sim, quando me canso muito penso no estado mineral, repouso sem morrer.

Daí que, como dissemos, dentro da inclinação para a coagulação da fala está presente o desejo de que esta supressão possa representar o instante em que ela deixa de ser necessária, como se todos os hiatos que existiam para que a linguagem tivesse sua razão de ser pudessem ter sido suprimidos. Situação ideal, latência nostálgica que auscultamos nos textos de Noll, mas que esses mesmos textos, porém, só chegam a aludir, nunca a desenvolver. Por isso, não sabemos o que poderá ocorrer ao protagonista de Harmada que, no final do romance, ao retornar para casa, encontra uma criança surda e muda morando no seu apartamento. Ao final, o próprio protagonista perde a fala: "Olhei para o garoto, aguardando receber dele alguma indicação para que eu pudesse inventar o que dizer. Da boca não me saía palavra. Eu parecia ter me contagiado pelo silêncio do garoto.” ${ }^{22}$ Em Berkeley, o protagonista também termina com uma criança, andando por entre uma espécie de abrigo para estrangeiros refugiados de uma guerra. Lá, a possibilidade de comunicação é quase anulada: "é como deve ser um surdo-mudo, só a inteligência xucra investigando a imagem, e no mais vivendo apenas para estranhar o conteúdo misterioso da boca em movimento [...] do meu lado direito tudo atuava em franca pantomima." ${ }^{23}$ Em Hotel atlântico, o protagonista termina ao lado de Sebastião, o enfermeiro que o ajudou na última fuga da história, que termina de frente para o mar, onde em poucos instantes o narrador perde a audição e a visão:

Eu sabia que Sebastião caminhava, eu sabia de tudo, normalmente, mas já não possuía audição. O mundo tinha ficado mudo, era só silêncio [...] Depois eu fiquei cego, não via mais nem o mar nem Sebastião. [...] Nesses segundos em que enchia o pulmão de ar, senti a mão de Sebastião apertar a minha. ${ }^{24}$

21. NOLL, 1996, p. 127.

22. NOLL, 2003, p. 101

23. NOLL, 2003, p. 104

24. NOLL, 1995, p. 106 
Da mesma forma, no final de $A$ céu aberto há o "encontro" com a figura da criança, muito embora ela surja através de uma rápida visão que logo se desvanece:

Ergui de leve a cabeça e vi uma menina vestida como que uma princesa hindu olhando para mim com um certo sorriso oculto. Uma criança toda morena de véu rosado e longas vestes. Cerrei os olhos... quando voltei a abri-los a menina não estava mais. Sentei-me no chão e comecei a chorar. $^{25}$

O protagonista encena o silêncio diante dos policiais. Mais uma vez o não encerramento "finge" o encerramento da narrativa. De fato, o ser, que em Noll é devir perpétuo, quer chegar a um destino identitário, uma coincidência consigo mesmo. A fala que flui "deseja" o silêncio. Porém, na narrativa de Noll, tudo se passa como se essa impossibilidade quisesse dizer que existir é sempre busca, nunca realização e encerramento. A criança, ou os sucedâneos dela (como Sebastião), figuras que encarnam a angelical simbologia da pureza, oferece a mão como um sinal de redenção ao mutilado, àquele que está teluricamente "sujo" da existência mundana, cujo corpo é o registro da ação do tempo e da errância infinda. Mas essa redenção não chega a se consumar e tal perspectiva sobrevive como uma latência interna à narrativa, um horizonte que se distancia a cada passo dado. Daí que, nos romances examinados, essas figuras infantis estejam rodeadas de mistério e inverossimilhança. De onde vem a criança surda-muda que está sozinha habitando o apartamento do narrador de Harmada? Por que o protagonista de $A$ céu aberto vê a imagem de uma garotinha que some logo em seguida fazendo-o cair em prantos? A mão redentora, como dissemos, é uma espécie de miragem impossível. Sua fugacidade é como a oscilação do desejo, que, por definição, nunca é totalmente encontradiço. Por isso, as histórias de Noll não têm como nos apresentar a figura do sujeito conciliado, justamente porque ela é a manifestação de um projeto de literatura que quer a qualquer custo fugir do engodo da "grande mentira da unidade" e, por que não, da grande mentira da identidade, da verdade e da "sabedoria" enquanto experiência de uma tradição, da qual falava Benjamin? A narrativa de Noll é registro e assunção (no sentido de assumir algo) dessa "pobreza" e dessa "barbárie" (tal como a abordamos aqui) que, ao passo que aponta para o 
vazio, desvela, ao mesmo tempo, uma inconfessa e não indicada possibilidade de construção.

Abstract: Discussion about the writing problem of João Gilberto Noll as of the presupposition that it is a registry of experience and memory weakening, components which give support to the Narrator figure, according to Walter Benjamin. The text intends to enquire about the way as the narrator problematic is configured in the Noll work, concerning to "lack of having what narrates", a sort of emblematic paradox of the conjuncture whose gaucho writer work is inserted. It is also a question about the kind of attitude the Noll writing offers as an answer for that conjuncture. The corpus is composed of four novels: Hotel atlântico, A céu aberto, Harmada and Berkeley em Bellagio.

Keywords: narrator, experience, João Gilberto Noll.

\section{Referências Bibliográficas}

BENJAMIN, Walter. Experiência e pobreza. In: Magia e técnica, arte e política. Tradução de Sérgio Paulo Rouanet. 5. ed. São Paulo: Brasiliense, 1993.

BENJAMIN, Walter. A modernidade e os modernos. 2. ed. Tradução de Heindrun Krieger Mendes da Silva, Arlete Brito e Tânia Jatobá. Rio de Janeiro: Tempo Brasileiro, 2000 .

BENJAMIN, Walter. O narrador. In: Magia e técnica, arte e política. Tradução de Sérgio Paulo Rouanet. 5. ed. São Paulo: Brasiliense, 1993. p. 197-221.

MARCHEZAN, Luiz Gonzaga. O hipotexto de Noll. Revista de Literatura Comparada, ABRALIC, Rio de Janeiro, n. 9, p. 229-242, 2006.

NOLL, João Gilberto. A céu aberto. São Paulo: Companhia das Letras, 1996.

NOLL, João Gilberto. Berkeley em Bellagio. São Paulo: Francis, 2003.

NOLL, João Gilberto. Harmada. São Paulo: Francis, 2003.

NOLL, João Gilberto. Hotel Atlântico. Rio de Janeiro: Francisco Alves, 1995.

VILlAÇA, Nizia. Paradoxos do pós-moderno. Rio de Janeiro: Editora da UFRJ, 1996. 